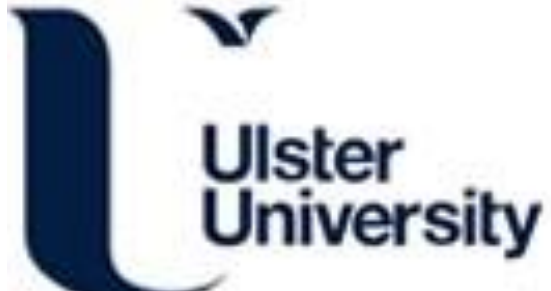

\section{Anger, Guilt and Shame as Mediators in the Relationship Between war Experiences and PTSD: Testing the Moderating Role of Child Soldier Status}

Murphy, S., Elklit, A., Dokkedahl, S., \& Mark, S. (Accepted/In press). Anger, Guilt and Shame as Mediators in the Relationship Between war Experiences and PTSD: Testing the Moderating Role of Child Soldier Status. Journal of Child and Adolescent Trauma, 10. https://doi.org/DOI

Link to publication record in Ulster University Research Portal

Published in:

Journal of Child and Adolescent Trauma

Publication Status:

Accepted/In press: 03/12/2016

DOI:

DOI

\section{Document Version}

Author Accepted version

\section{General rights}

Copyright for the publications made accessible via Ulster University's Research Portal is retained by the author(s) and / or other copyright owners and it is a condition of accessing these publications that users recognise and abide by the legal requirements associated with these rights.

\section{Take down policy}

The Research Portal is Ulster University's institutional repository that provides access to Ulster's research outputs. Every effort has been made to ensure that content in the Research Portal does not infringe any person's rights, or applicable UK laws. If you discover content in the Research Portal that you believe breaches copyright or violates any law, please contact pure-support@ulster.ac.uk. 
Anger, Guilt, and Shame as Mediators in the Relationship between War Experiences and PTSD: Testing the Moderating Role of Child Soldier Status

Siobhan Murphy, Ask Elklit, and Sarah Dokkedahl National Centre of Psychotraumatology, University of Southern Denmark Mark Shevlin

Psychology Research Institute, Ulster University

Author Note

Siobhan Murphy, National Centre of Psychotraumatology, University of Southern Denmark, Odense, Denmark; Ask Elklit, National Centre of Psychotraumatology, University of Southern Denmark, Odense, Denmark; Sarah Dokkedahl, National Centre of Psychotraumatology, University of Southern Denmark, Odense, Denmark; Mark Shevlin, Psychology Research Institute, Ulster University, Magee Campus, Northern Ireland.

Correspondence concerning this article should be addressed to Siobhan Murphy, National Centre of Psychotraumatology, Department of Psychology, University of Southern Denmark. E-mail: smurphy@health.sdu.dk

Brief Author Bios

Siobhan Murphy $(\mathrm{PhD})$ is a Postdoctoral Researcher at the National Centre of Psycholotraumatology, University of Southern Denmark. Ask Elklit (MSc) is a Professor at the National Centre of Psycholotraumatology, University of Southern Denmark, Sarah Dokkedahl (BSc) is a student worker in National Centre of Psychotraumatology, University 
of Southern Denmark. Mark Shevlin $(\mathrm{PhD})$ is a Professor at Ulster University, Northern Ireland.

RECEIVED: May 12, 2016

REVISION DATE: September 1, 2016

ACCEPTANCE DATE: September 7, 2016 


\begin{abstract}
Previous research has identified strong associations between war experiences and posttraumatic stress disorder (PTSD). Few studies, however, have explored the underlying mechanisms of these associations in an integrated model. This study explored whether feelings of anger, shame and guilt, mediated the effects of war experiences and PTSD and if this association is heightened in former child soldiers from Northern Uganda. Nearly $40 \%$ of the sample were former child soldiers $(N=122)$, and 189 were civilians. A total of $35.5 \%$ met the proposed $I C D-11$ criteria for PTSD. Findings indicated previous war experiences were directly associated with PTSD. Anger and guilt were significant mediators of this effect, child soldier status did not moderate the mediated effects. This study provides an alternative framework of assessing the association between trauma and PTSD using a sample of young adults exposed to mass conflict.

Keywords: posttraumatic stress disorder, former child soldiers, anger, guilt, shame, moderated mediation
\end{abstract}


Anger, Guilt, and Shame as Mediators in the Relationship between War Experiences and PTSD: Testing the Moderating Role of Child Soldier Status

Recent changes to the diagnostic criteria for posttraumatic stress disorder (PTSD) in the Diagnostic Statistical Manual for Mental Disorders-5 (DSM-5: American Psychiatric Association, 2013) and the proposed changes in the upcoming International Classification of Diseases (ICD-11, World Health Organisation) have increased research attention in the area of PTSD. The two classification systems differ in their approaches, with the DSM-5 extending the diagnostic criteria to 20 symptoms whilst the ICD-11 intends to reduce the criteria to six symptoms. PTSD as outlined in the DSM-5 provides a comprehensive profile of posttraumatic reactions and includes an additional cluster of symptoms relating to negative alterations in cognition and mood (Criterion D). The ICD-11 intends to adopt a more specific approach and maintains the three symptom clusters of re-experiencing, avoidance of traumatic reminders, and hyperarousal symptoms (Maercker et al., 2013). Further, the inclusion of an additional trauma-related disorder called Complex-PTSD has been proposed to capture symptoms associated with negative self attributes (e.g., guilt and shame), affect regulation, and relational difficulties. Differences in prevalence rates between the two classification systems have been reported with studies indicating higher rates of PTSD according to DSM-5 than ICD-11 (Hansen, Hyland, Armour, Shevlin, \& Elklit, 2015; O’Donnell et al., 2014).

From 1986 to 2007, Northern Uganda experienced over 20 years of civil conflict between the Ugandan government and the Lord's Resistance Army (LRA). This period was marked by serious human rights violations, the deaths of approximately 200,000 people, and high levels of poverty across the country (Klasen, Reissmann, Voss, \& Okello, 2015). It is estimated that over 2 million people were internally displaced (IDPs) and relocated to camps that were characterised by chronic over-crowding, insecurity, fear, social problems, and high 
morbidity and mortality rates (Roberts et al., 2008). Additionally, many children were abducted and used as child soldiers in the LRA. During their time in captivity, children endured extreme acts of violence, including physical torture, severe deprivation, and sexual abuse. Further, they were forced to commit atrocities against each other and their own communities including: killing family members and other civilians; raids on villages; and looting (Amone-P’Olak et al., 2013; Mugisha, Muyinda, Wandiembe, \& Kinyanda, 2015). The psychosocial outcomes of former child soldiers have been documented with studies reporting heterogeneity across rates of PTSD (Betancourt et al., 2013). There is a paucity of studies, however, that have compared PTSD in child soldiers and civilians and the possible underlying mechanisms that may contribute to the development of PTSD.

Child soldiers often are faced with the most dangerous tasks in which they are both victims and perpetrators of high levels of violence (Pham, Vinck, \& Stover, 2009). Exposure to severe and traumatic stress may lead to the development of PTSD and other psychological and social problems. Evidence suggests that such experiences can alter former child soldiers' perceptions of violence in that it becomes normalised and can lead to higher levels of aggression and PTSD severity (Elbert, Weierstall, \& Schauer, 2010; Hermenau, Hecker, Maedl, Schauer, \& Elbert, 2013). Further, while some studies have indicated that aggression plays a protective role in PTSD severity (Weierstall, Schaal, Schalinski, Dusingizemungu, \& Elbert, 2011), others have found the protective effect is only evident below a certain threshold of traumatic experiences (Weierstall, Bueno Castellanos, Neuner, \& Elbert, 2013). Extant literature conducted on veteran samples have reported higher levels of anger control and hostility among veterans with PTSD compared to veterans without PTSD (e.g., Castillo, Baca, Conforti, Qualls, \& Fallon, 2002). For example, Novaco and Chemtob (2002) examined the association of anger and combat-related PTSD in a sample of Vietnam veterans. Findings indicated that while controlling for age, education, and combat exposure, 
anger accounted for over $40 \%$ of the variance in PTSD and that anger differentiated PTSD from non-PTSD combat veterans. This finding was replicated in a sample of Iraq and Afghanistan war veterans that found those with PTSD reported significantly greater anger and hostility than those in the subthreshold-PTSD and non-PTSD groups (Jakupcak et al., 2007). However, feelings of anger are not limited to veteran samples with findings of metaanalytical reviews, demonstrating a strong relationship between PTSD and anger and hostility among a range of trauma-exposed adults (Orth \& Wieland, 2006).

From a treatment perspective, a better understanding of the role of anger in PTSD has several important implications that may negatively impact the treatment of PTSD and require more tailored interventions. Foa, Riggs, Massie, and Yarczower (1995) found support for this theory in a sample of female assault victims with PTSD. They found those who reported higher PTSD severity pre-treatment displayed more intense facial fear expressions during the first reliving of the assault task and benefitted more from treatment than those with less severe PTSD and displayed less fear. Conversely, assault victims who reported pre-treatment anger were more likely to display less fear expression during the reliving task and had a poorer treatment outcome. In another study using a veteran sample undergoing cognitive therapy, Owens, Chard, and Cox (2008) assessed the changes in maladaptive cognitions, anger expression, PTSD, and depression. They found moderate and high levels of pretreatment anger affected the individual's ability to make cognitive reappraisals required to reduce their PTSD symptoms.

Cognitive models of PTSD outline that the development of negative self and other evaluations following traumatic events leads to maladaptive cognitive processing of the event and the onset of PTSD symptomology (Clark \& Beck, 2010; Ehlers \& Clark, 2000). Traumarelated cognitions such as guilt and shame are common in survivors of war (Leskela, Dieperink, \& Thuras, 2002; Stotz, Elbert, Müller \& Schauer, 2015) and associated with 
PTSD (Pugh, Taylor, \& Berry, 2015). Feelings of shame and guilt are also prominent features of moral injury, a recent construct recognised within war affected populations (Litz et al., 2009). Moral injury captures a broader range of veteran reactions, such as guilt, shame, anger, relational and existential problems, and social isolation, all of which emerge following witnessing and/or participating in war conflict (Currier, Holland, \& Malott, 2015). Further, a recent review concluded that symptoms of shame and guilt following moral injury mediates the onset of PTSD (Nazarov et al., 2015).

Feelings of guilt have been implicated as a causal mechanism in the development and maintenance of PTSD and PTSD symptom severity (Kubany \& Watson, 2003). Marx and colleagues (2010) examined the mediating role of trauma-related guilt in a male veteran sample exposed to combat violence. Findings indicated that guilt partially mediated the association between combat exposure violence and PTSD. Subsequent analyses comparing veterans who were actively involved in combat violence to those who witnessed the violence found guilt fully mediated the relationship. Browne, Evangeli, and Greenberg (2012) investigated the relationship between work-related traumatic exposure, guilt cognitions, and PTSD symptoms among journalists in conflict areas and found that guilt mediated this association. Fewer studies, however, have investigated the role of trauma-related guilt in former child soldiers. In one study, Klasen and colleagues (2015) found that guilt was a significant predictor of PTSD in child soldiers who identified themselves as perpetrators in comparison to those who identified as victims. This finding contrasts to previous studies that have found that both victim and perpetrator status during war experiences contribute to the formation of trauma-related guilt (Kubany et al., 1996).

Another trauma-related cognition associated with PTSD is shame (Andrews, Brewin, Rose, \& Kirk, 2000; Beck et al., 2011; Leskela et al., 2002). Whilst the role of shame in PTSD has received less attention than guilt, some studies have found that shame rather than 
guilt was significantly associated with PTSD (Ginzburg et al., 2009; Leskela et al.). Beck and colleagues (2011) explored the relationship between both guilt and shame and PTSD in a sample of females exposed to intimate partner violence. Findings indicated that shame, and trauma-related guilt cognitions, were associated with PTSD. However, subsequent moderation analyses indicated that shame interacted with IPV in association with PTSD whereas trauma-related guilt cognitions did not.

The current study aims to build on the existing literature to examine the indirect effects of feelings of anger, shame, and guilt on the relationship between war experiences and PTSD in a sample of former child soldiers and civilians from Northern Uganda. The study is predicated on the following hypotheses: (1) War experiences were predicted to be directly associated with PTSD; (2) Feelings of anger, shame, and guilt were predicted to mediate this relationship; and (3) These associations were expected to be heightened (moderated) by child soldier status. The overarching hypothesis was that child solider status would moderate the direct effect between early war experiences and PTSD and also the indirect associations via feelings of anger, shame, and guilt.

\section{Methods}

\section{Sample}

This cross-sectional study was conducted in Gulu, in the subcounty of Awach, the biggest district of Northern Uganda. The sample $(N=314)$ included both males $(49 \%)$ and females $(51 \%)$ aged between 18 and 25 years $(M=22.30)$. Those in this age group were still children when the war was ongoing. The majority of the sample lived with either one or both parents (38.9\% and 39.5\%, respectively). Nearly $40 \%$ of the participants were former abductees from the LRA $(N=122)$, while the remaining participants were never abducted (NA) civilians $(N=189)$. The age of abduction ranged from 4 to 18 years old (mean age of abduction was 11.06 years) and the duration ranged from 1 day to 14 years (with a mean 
duration of 3.2 years). The lack of a national register in Uganda made random sampling difficult. The local leaders (LL) of the four parishes in Awach therefore selected the participants based on the principles of random sampling. The LLs selected the number of participants in accordance to the size of the parish. Participants were further selected equally from each village within the parish with equal participation between gender, age, and former child soldiers and civilians. This allowed for a broad distribution of participants within the Awach community.

Participants gave written consent to their participation, and those who could not write were asked to sign with their thumbprint in ink. Before giving consent, the participants were informed about the content of the study, their rights to decline and withdraw at any time, and the confidentiality of their participation in the study. None of the participants who were selected declined to participate. The Institutional Review and Ethics Committee at the Lacor Hospital in Gulu approved the project along with the translations. All measures and instruments were translated and back-translated from English into Luo, the local language of the Awach community spoken by the Acholi tribe.

The questionnaires were read out loud for the participants to avoid any possible reading disabilities in the rural areas of Northern Uganda. Local field assistants asked the questions in the local language, Luo. The interviews took place at the homes of the participants.

\section{Measures}

\section{United Nations Children's Fund (UNICEF B\&H) War Trauma Screening Scale}

(UNICEF, 2010). Trauma exposure was measured using the UNICEF War Trauma

Screening Scale, which was originally developed for Bosnia but has been adapted for use in West African war-affected youth (Amone-P'Olak et al., 2013). The instrument consists of items relating to personal injury (6 items), witnessing violence (11 items), injuries and threats 
to self (5 items), deaths ( 7 items), physical threats to loved ones (4 items), material losses (4 items), harm to loved ones (4 items), separation ( 2 items), displacement (5 items), participating in armed groups ( 4 items), and sexual abuse (3 items). In the current study, the reliability estimate for the total scale was high (Cronbach's alpha $=.93$ ).

\section{ICD-11 Trauma Questionnaire (ICD-11 TQ Version 1.4; Cloitre, Roberts,}

Bisson, \& Brewin, unpublished manuscript). This measure is currently under development and designed to capture the ICD-11 diagnoses of PTSD and CPTSD. Six questions based on the three core elements of PTSD: Re-experiencing the traumatic event (2/3 items), avoidance ( 2 items), and excessive sense of current threat ( 2 items). The re-experiencing scale can include a third item that corresponds to feeling upset in response to internal or external cues that symbolize or resemble an aspect of the traumatic event. This item was designed to allow re-experiencing to be assessed among respondents with absent or unclear memories of the traumatic event (e.g., childhood abuse) and was used in the current study. The response format corresponds to the degree the symptoms bothered the individual in the past month and are rated on a 5-point Likert scale (where $0=$ not at all, $1=$ a little bit, $2=$ moderately, $3=$ quite a bit, and $4=$ extremely). Diagnostic rates are determined by scoring $\geq 2$ in at least one symptom from the three clusters. In the current study, the reliability estimates were adequate with Cronbach's alphas for PTSD total scale $(\alpha=.91)$, re-experiencing $(\alpha=.80)$, avoidance $(\alpha=.63)$, and hypervigilance $(\alpha=.85)$.

\section{Mediating Variables}

The mediating variables (shame, guilt, and anger) were derived from the ICD-11 TQ (Cloitre et al., unpublished manuscript). Shame was measured using the question, "I often feel ashamed of myself whether it makes sense or not." The response format was rated on a 5-point Likert scale where $0=$ not at all, $1=$ a little bit, $2=$ moderately, $3=$ quite a bit , and 4 $=$ extremely. 
Guilt was measured using the question, "I feel guilty about things I have done or failed to do." The response format was rated on a 5-point Likert scale where $0=$ not at all, $1=$ a little bit, 2 = moderately, $3=$ quite $a$ bit, and $4=$ extremely.

Anger was measured using the question, "I experience episodes of uncontrollable anger." The response format was rated on a 5-point Likert scale where $0=$ not at all, $1=a$ little bit, $2=$ moderately, $3=$ quite a bit, and $4=$ extremely.

\section{Analytical Plan}

The overall model was tested using conditional process analysis and tested using SPSS 22 running the PROCESS macro (Hayes, 2012). The statistical significance of the mediated, moderated, and moderated mediated effects were calculated using the bootstrapping (10,000 samples) method. Using this approach, the data is resampled to create an empirical approximation of the sampling distribution of the statistic. Consequently, point estimates and $95 \%$ confidence intervals were created for the conditional indirect and direct effects. Statistical significance was determined when zero was not within the $95 \%$ confidence intervals. The empirically based confidence intervals used in this study should therefore avoid making incorrect inferences about statistical significance. The index of moderated mediation test describes how the indirect effect of the independent variable on the dependent variable through the mediator(s) is linearly related to the moderator. The purpose of this inferential test is to confirm whether an indirect effect is in fact moderated by estimating whether indirect effects (constructed by model coefficients) at different values of the moderator are statistically different from each other (Murphy, Murphy, \& Shevlin, 2015). The moderated mediation model is presented in Figure 1. 
Figure 1. A moderated mediation model of the association between war experiences and PTSD.

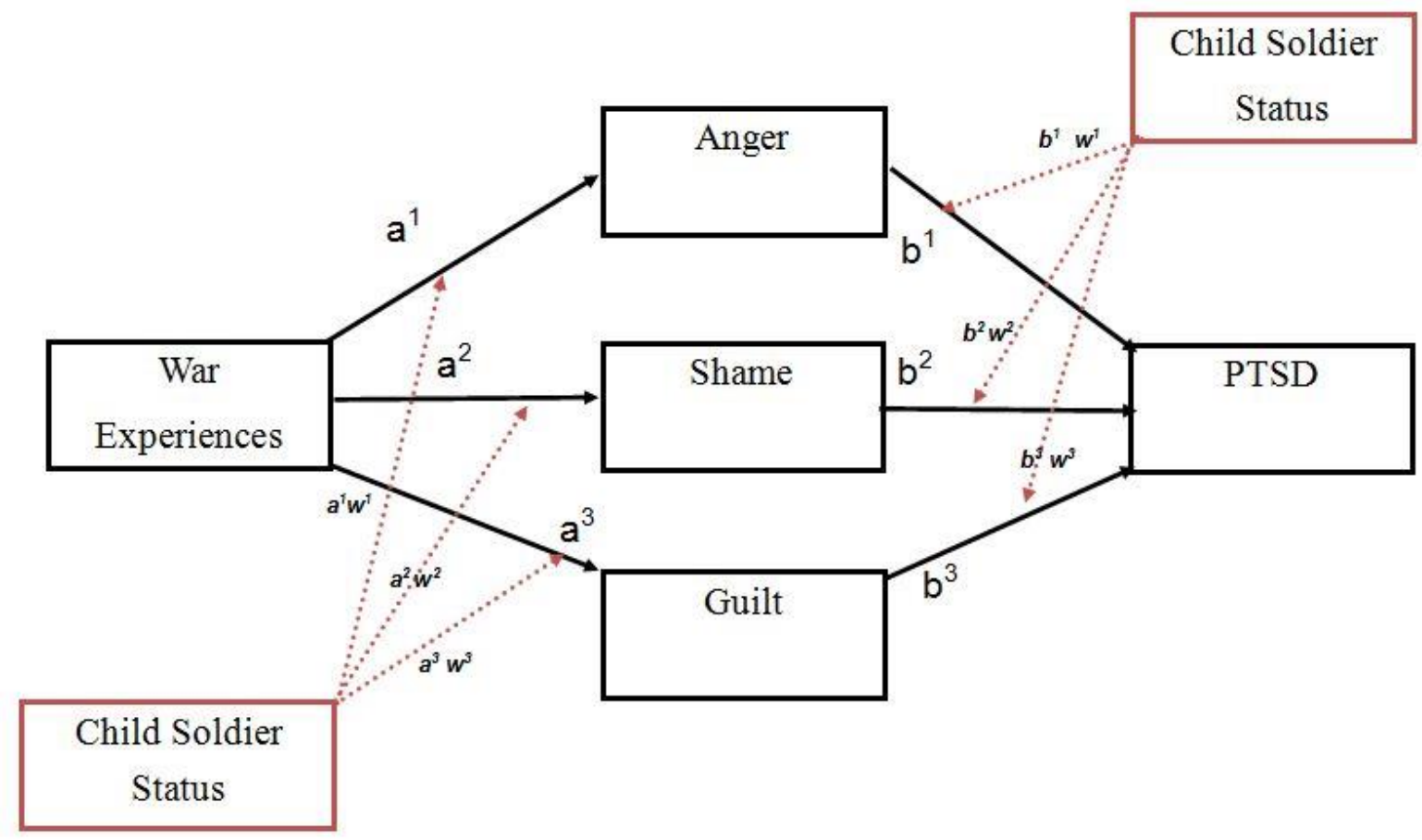

Note: Child Soldier Status variable duplicated to avoid diagrammatic clutter.

\section{Results}

A total of $35.5 \%$ of the sample met the ICD-11 criteria for PTSD using the ICD-11 Trauma Questionnaire. Chi-square analysis indicated that there was no significant difference between gender and $\operatorname{PTSD}\left(\chi^{2}(1)=1.10, \mathrm{p}>.05\right)$. However, there was a significant difference between former child soldiers and civilians in scoring positive for $\operatorname{PTSD}\left(\chi^{2}(1)=\right.$ 11.10, $\mathrm{p}<.005)$. Table 1 shows the frequencies of PTSD items using the binary variable format. For the total sample items relating to PTSD, re-experiencing symptoms were the most commonly endorsed experiences, while symptoms of PTSD internal avoidance were the least commonly endorsed item. 
Table 1.

ICD-11 TQ PTSD Endorsement Rates

\begin{tabular}{llcc}
\hline ICD-11 & Item & N & $\%$ \\
\hline PTSD 1 & $\begin{array}{l}\text { Upsetting dreams that replay part of the event or are clearly related } \\
\text { Re-Exp }\end{array}$ & 202 & 64.5 \\
to the event? & & \\
PTSD 2 & $\begin{array}{l}\text { Powerful images or memories that sometimes come into your mind } \\
\text { Re-Exp }\end{array}$ & 145 & 46.3 \\
PTSD 3 & $\begin{array}{l}\text { Feeling very upset when something reminded you of the stressful } \\
\text { experience? }\end{array}$ & 184 & 59.0 \\
Re-Exp & Aveel the event is happening again in the here and now? & & \\
PTSD 4 & Avoiding internal reminders of the stressful event experience (for & 123 & 39.4 \\
Avoid & example, thoughts, feelings, or physical sensations)? & & \\
PTSD 5 & $\begin{array}{l}\text { Avoiding external reminders of the stressful event experience (for } \\
\text { Avoid }\end{array}$ & 142 & 45.8 \\
example, people, places, conversations, objects, activities, or & & \\
PTSD 6 & Beituations)? & 125 & 40.1 \\
Arousal & "super-alert", watchful, or on guard? & 133 & 42.5 \\
PTSD 7 & Feeling jumpy or easily startled? & & \\
Arousal & & & \\
\hline
\end{tabular}

Table 2 shows the mean scores and correlations for the variables separately for civilians and former child soldiers; child soldiers reported significantly higher war experiences, feelings of shame and guilt, and higher PTSD scores. There were no differences between the two groups in terms of feelings of anger. Anger was not significantly correlated with child solider status. The remaining correlations were all low and statistically significant with the war experiences displaying a stronger correlation.

Table 2. 
Descriptive Statistics and Correlations among Study Variables Comparing Civilians and Child Soldiers

From Path $\quad \beta(\mathrm{S} . \mathrm{E})$ P-value $\quad \mathrm{t} \quad 95 \% \mathrm{CI}$

\begin{tabular}{lllll}
\hline & $\begin{array}{l}\text { Civilian } \\
(N=189,60.8 \%) \\
\text { Mean } \\
(\mathrm{SD})\end{array}$ & $\begin{array}{l}\text { Child Solider } \\
(N=122,39.2 \%) \\
\text { Mean } \\
(\mathrm{SD})\end{array}$ & $t(\mathrm{df}) p$ & $\begin{array}{l}\text { Correlations with } \\
\text { Child Soldier } \\
\text { Status }\end{array}$ \\
\hline War & 29.93 & 41.77 & $-13.63(307)^{* * *}$ & $.61^{* *}$ \\
Experiences & $(8.55)$ & $(5.37)$ & $-1.78(298)$ & .10 \\
Anger & 2.04 & 2.34 & & \\
& $(1.44)$ & $(1.42)$ & $-4.26(301)^{* * *}$ & $.24 * *$ \\
Shame & 1.20 & 1.84 & & $.20 * *$ \\
Guilt & $(1.30)$ & $(1.27)$ & $-3.57(305)^{* * *}$ & \\
& 1.70 & 2.25 & & \\
& $(1.36)$ & $(1.25)$ & $-5.15(308)^{* * *}$ & $.28 * *$ \\
PTSD & 2.84 & 4.17 & &
\end{tabular}

The unstandardised estimates from the mediation model are displayed in Table 3 . The results showed that the regression coefficients for the hypothesised mediation variables shame (path a1), guilt (path a2), and anger (path a3) on war experiences were statistically significant. Child soldier status was not significantly associated with any of the mediating variables (pathway w1-w3). In examining the interactions between war experiences and each mediator again, child soldier status did not moderate the relationships. 


\begin{tabular}{|c|c|c|c|}
\hline \multicolumn{4}{|l|}{ Mediating Paths } \\
\hline WE-Shame & $0.04(0.01)^{* * *}$ & 3.49 & $0.02,0.06$ \\
\hline WE-Guilt & $0.04(0.01)^{* * *}$ & 3.25 & $0.01,0.06$ \\
\hline WE-Anger & $0.04(0.01)^{*}$ & 2.80 & $0.01,0.06$ \\
\hline \multicolumn{4}{|l|}{ Moderating Paths } \\
\hline CSS-Shame & $-0.09(1.05)^{\mathrm{ns}}$ & -0.09 & $-2.15,1.97$ \\
\hline CSS-Guilt & $1.19(1.08)^{\mathrm{ns}}$ & 1.10 & $-0.94,3.32$ \\
\hline CSS-Anger & $0.42(1.19)^{\mathrm{ns}}$ & 0.35 & $-1.92,2.76$ \\
\hline \multicolumn{4}{|l|}{ Interaction } \\
\hline WE-CSS-Shame $a^{1} w^{1}$ & $0.01(0.03)^{\mathrm{ns}}$ & 0.28 & $-0.04,0.06$ \\
\hline WE-CSS-Guilt $\quad \mathrm{a}^{2} \mathrm{w}^{2}$ & $-0.03(0.03)^{\mathrm{ns}}$ & -0.97 & $-0.08,0.03$ \\
\hline WE-CSS-Anger $\mathrm{a}^{3} \mathrm{w}^{3}$ & $-0.01(0.03)^{\mathrm{ns}}$ & -0.44 & $-0.07,0.04$ \\
\hline
\end{tabular}

Table 3.

Estimates of Direct Effects and Interactions from the Moderated Mediation

Note: $* * * p=<.001, * * p=<.005, * p=<.05 \mathrm{WE}=$ War Experiences, CSS $=$ Child Soldier Status, PTSD $=$ Posttraumatic Stress Disorder.

Table 4 shows that the direct path (path c) from war experiences to PTSD was statistically significant. The model also showed that for the mediators (feelings of guilt and anger) the regression coefficients, while controlling for war experiences, were also significantly associated with PTSD. Feelings of shame, however, were not significantly associated with PTSD. In terms of moderated mediators (interactions), no significant relationships emerged.

Table 4.

Direct and Indirect Effects from the Moderated Mediation Model

\begin{tabular}{lllll}
\hline Variable & Path & $\beta($ S.E) & t & $95 \%$ CI \\
\hline
\end{tabular}




\begin{tabular}{|c|c|c|c|c|}
\hline \multirow{2}{*}{ Direct Effect } & & \multicolumn{3}{|l|}{$p$-value } \\
\hline & & & & \\
\hline WE-PTSD & $\mathrm{c}$ & $0.07(0.02)^{* * *}$ & 4.01 & $0.03,0.10$ \\
\hline $\mathrm{WE}^{*} \mathrm{CSS}$ & $c^{1} x^{4}$ & $0.04(0.04)$ & 0.97 & $-0.04,0.11$ \\
\hline \multicolumn{5}{|c|}{ Mediating Paths to PTSD } \\
\hline Shame-PTSD & $b^{l}$ & $0.21(0.12)^{\mathrm{ns}}$ & $1.72^{\mathrm{ns}}$ & $-0.03,0.46$ \\
\hline Guilt-PTSD & $b^{2}$ & $0.57(0.11)^{* * *}$ & 5.14 & $0.35,0.78$ \\
\hline Anger-PTSD & $b^{3}$ & $0.24(0.11)^{*}$ & 2.19 & $0.02,0.45$ \\
\hline \multicolumn{5}{|c|}{ Moderating Path to PTSD } \\
\hline CSS-PTSD & $\mathrm{w}^{5}$ & $-1.8(1.57)^{\mathrm{ns}}$ & $-1.15^{\mathrm{ns}}$ & $-4.88,1.28$ \\
\hline \multicolumn{5}{|c|}{ Interaction with PTSD } \\
\hline Shame*CSS & $b^{1} \times w^{5}$ & $0.24(0.20)^{\mathrm{ns}}$ & $1.18^{\mathrm{ns}}$ & $-0.16,0.63$ \\
\hline Guilt*CSS & $b^{1} \times w^{6}$ & $-0.06(0.19)^{\mathrm{ns}}$ & $-0.30^{\mathrm{ns}}$ & $-0.44,0.32$ \\
\hline Anger*CSS & $b^{1} x w^{7}$ & $-0.05(0.17)^{\mathrm{ns}}$ & $-0.28^{\mathrm{ns}}$ & $-0.37,0.28$ \\
\hline
\end{tabular}

Note: $* * * p=<.001, * * p=<.005, * p=<.05 \mathrm{WE}=$ War Experiences, CSS $=$ Child Soldier Status, PTSD $=$ Posttraumatic Stress Disorder.

Table 5 reveals that the direct effect was significant for civilians and child soldiers.

The results further show that the conditional indirect effects of war experiences on PTSD were significant for feelings of shame and anger. These effects were statistically significant for both civilians and former child soldiers. In terms of feelings of guilt, there was a significant effect for civilians but not former child soldiers. The index of moderated mediation (see Table 6) revealed that moderated mediation did not occur for any of the study variables, indicating that the difference in effect sizes between civilians and former child soldiers were marginal.

Table 5.

Conditional Direct and Indirect Effects for Civilians and Child Soldiers 


\begin{tabular}{|c|c|c|c|c|c|c|c|c|}
\hline & \multicolumn{2}{|c|}{$\begin{array}{l}\text { WE-PTSD } \\
\text { (direct effects) }\end{array}$} & \multicolumn{2}{|c|}{$\begin{array}{l}\text { WE-Shame-PTSD } \\
\text { (indirect effects) }\end{array}$} & \multicolumn{2}{|c|}{$\begin{array}{l}\text { WE-Guilt-PTSD } \\
\text { (indirect effects) }\end{array}$} & \multicolumn{2}{|c|}{$\begin{array}{l}\text { WE-Anger-PTSD } \\
\text { (indirect effects) }\end{array}$} \\
\hline & $\beta(\mathrm{SE})$ & $95 \% \mathrm{CI}$ & $\begin{array}{l}\beta \\
(\mathrm{SE})\end{array}$ & $95 \% \mathrm{CI}$ & $\begin{array}{l}\beta \\
(\mathrm{SE})\end{array}$ & $95 \% \mathrm{CI}$ & $\begin{array}{l}\beta \\
(\mathrm{SE})\end{array}$ & $95 \% \mathrm{CI}$ \\
\hline Civilian & $\begin{array}{l}0.03 \\
(.02)\end{array}$ & $\begin{array}{l}0.02- \\
0.05\end{array}$ & $\begin{array}{l}0.01 \\
(0.01)\end{array}$ & $\begin{array}{l}0.00- \\
0.02\end{array}$ & $\begin{array}{l}0.02 \\
(0.01)\end{array}$ & $\begin{array}{l}0.01 \text { - } \\
0.04\end{array}$ & $\begin{array}{l}0.01 \\
(0.00)\end{array}$ & $\begin{array}{l}0.00 \text { - } \\
0.02\end{array}$ \\
\hline $\begin{array}{l}\text { Child } \\
\text { Soldier }\end{array}$ & $\begin{array}{l}0.06 \\
(0.02)\end{array}$ & $\begin{array}{l}0.03- \\
0.10\end{array}$ & $\begin{array}{l}0.02 \\
(0.01)\end{array}$ & $\begin{array}{l}0.00- \\
0.05\end{array}$ & $\begin{array}{l}0.01 \\
(0.01)\end{array}$ & $\begin{array}{l}-0.02 .- \\
0.04\end{array}$ & $\begin{array}{l}0.00 \\
(0.01)\end{array}$ & $\begin{array}{l}0.00- \\
0.02\end{array}$ \\
\hline
\end{tabular}

Note: Significant effects in bold.

Table 6.

Index of Moderated Mediation

\begin{tabular}{llll}
\hline Mediator & Index & SE (Boot) & $95 \%$ CI \\
\hline Shame & 0.01 & 0.01 & $-0.01-0.04$ \\
Guilt & -0.02 & 0.02 & $-0.04-0.02$ \\
Anger & 0.00 & 0.01 & $-0.02-0.01$ \\
\hline
\end{tabular}

\section{Discussion}

The current study aimed to test three interlinked hypotheses. Firstly, war experiences were predicted to be directly associated with PTSD, and feelings of anger, shame, and guilt were then predicted to mediate this relationship. Finally, these associations were expected to be heightened by child soldier status. The current findings indicate $35.5 \%$ of the overall sample received a PTSD diagnosis in accordance with the new screening measure, which captures the proposed PTSD criteria for ICD-11. This figure is considerably higher than reported in a recent study from Northern Uganda that reported PTSD estimates of $11 \%$ (Mugisha et al., 2015). However, the PTSD estimates are likely higher given the high proportion of former child soldiers used in the current study. Another possible explanation is that the threshold used for endorsement of PTSD symptoms in the ICD-11 TQ is relatively low (rated as present with a score of $\geq 2$ ), which may account for the high levels of PTSD in 
the current study. Notably, there is considerable heterogeneity in PTSD estimates in populations exposed to civil conflict with estimates varying from $4 \%$ to $92 \%$ (c.f. Johnson \& Thompson, 2008, for a review). These conflicting estimates are likely due to different measures of PTSD and the time since conflict ended. In line with the first hypothesis, the results confirmed that war experiences significantly predicted PTSD. This compliments a large body of evidence demonstrating the effects of war trauma on PTSD in both civilian and former child soldiers (Bayer, Klasen, \& Adam, 2007; Roberts et al., 2008; Vinck et al., 2007).

Our second hypothesis was partially supported as the results demonstrated that, although there was a significant relationship between war experiences and feelings of shame, this relationship did not extend to PTSD. This finding contradicts previous studies that have highlighted the role of shame in traumatised populations (Andrews et al., 2000; Beck et al., 2011; Leskela et al., 2002). However, there were significant indirect effects for traumarelated guilt and feelings of anger. These results support a large body of evidence indicating the high rates of anger in populations exposed to war or mass conflict (Orth \& Wieland, 2006). Many theories have been developed to explain the anger-PTSD association. Chemtob and colleagues (1997) postulate a survival mode theory whereby individuals with PTSD have a lowered threshold for threat perception, which then activates a biologically prepared survival mode, including anger responses. Alternatively, Foa and colleagues (1995) developed the fear avoidance theory, which indicated individuals with PTSD avoid traumarelated fear emotions that are elicited by intrusive thoughts. The authors argue that traumabased anger therefore is a preferred emotional state because it has a more positive emotional valence than fear. (Foa et al., 1995)

The finding that guilt partially mediated the effects of war experiences is consistent with previous findings demonstrating the role of cognitive processes in the development of 
PTSD. Cognitive models of PTSD suggest that traumatic experiences can affect belief systems that lead to the development of negative schematic beliefs involving the self and the world, which can affect how individuals interpret and interact with their environment (Ehlers \& Clarke, 2000). In considering the role of guilt in cognitive models of PTSD, it can be argued that feelings of guilt may lead to maladaptive cognitive processing styles, such as rumination and avoidance of traumatic reminders, which then obstructs traumatic recovery. This has important treatment implications, as studies have shown reductions in trauma-related guilt cognitions and more positive PTSD recovery outcomes using a range of different trauma survivors. A recent randomised control trial conducted on former child soldiers in northern Uganda found that narrative exposure therapy was a superior intervention in treating PTSD and trauma-related guilt (Ertl, Pfeiffer, Schauer, Elbert, \& Neuner, 2011).

The third hypothesis, that child solider status would moderate the mediating effects of shame, guilt, and anger, was not supported. Although there is a paucity of research on angerrelated problems and feelings of guilt in former child soldiers, evidence suggests that externalising problems are attenuated in comparison to internalising problems (Klasen, Oettingen, Daniels, Post, Hoyer, \& Adam, 2010). An alternative explanation for these findings is that research has demonstrated that the cumulative severity of trauma exposure renders an individual more vulnerable to developing posttraumatic stress disorder (PTSD) and indicates a robust relationship between the magnitude of traumatic events and the severity of PTSD symptoms (Ai, Peterson, \& Ubelhor, 2002; Catani, Jacob, Schauer, Kohila, \& Neuner, 2008; Neuner et al., 2004; Schaal \& Elbert, 2006). Given the high levels of exposure to war experiences in both populations in the current study, these findings therefore support the empirical evidence of a 'building block' or threshold effect, which means higher exposure to traumatic stressors augments PTSD risk and symptom severity in a dose-response fashion (Kolassa, Ertl, Eckart, Kolassa, Onyut, \& Elbert, 2010; Neuner et al.). This suggests 
that the cumulative burden of traumatic experiences has an effect on the overall severity of PTSD rather than specific types of exposure, in this case, child soldier status or civilian status.

Another possible interpretation for the finding that child soldier status did not moderate the mediating mechanisms between war experiences and PTSD is that there are numerous factors that may contribute to the development of feelings of anger and guilt in post-conflict societies that persist regardless of direct involvement in hostilities. For example, factors such as preoccupation with injustices of the past following prolonged periods of deprivation and human rights violations, limited economic opportunities, land disputes, and bereavement are common in many post-conflict societies (Silove, 1999). This finding has been supported in other studies that demonstrate civil conflict and other post-war factors, such as displacement, death and disappearance of family members, inadequate housing, and poor healthcare, contribute to ongoing psychological distress in post-war environments (Amone-P'Olak et al., 2014; Miller \& Rasmussen, 2010).

The results of this study should be considered in light of some limitations. The ICD11 Trauma Questionnaire has yet to undergo psychometric testing and did not include indicators of functional impairment. Caution is therefore warranted in interpreting these findings. Importantly, it should be noted that the war experiences scale does not accurately reflect the severity of traumatic experiences former child soldiers specifically endured during the conflict and was used as an overall measure of war events. Further, the mediating variables were based on single item questions and do not accurately reflect the multi-faceted nature of each of the constructs. For example, in their systematic review of the role of guilt in PTSD, Pugh and colleagues (2015) outline the different theoretical issues surrounding the concept of guilt. Therefore, the results of the current study should be interpreted with this in mind and replicated using standardised measures of these variables. Another limitation to 
this study was the lack of random sampling and the selection of participants, which was due to the lack of a national register in Uganda. Also as the current findings are based on a sample of young adults from Northern Uganda, it is unknown how they will generalise to other populations. Finally, the cross-sectional nature of the study limits inferences regarding causality. Therefore, future research using longitudinal designs would improve the reliability of the associations reported in the current study.

To conclude, the current findings indicated that feelings of anger and guilt were significant mediators of the relationship between war experiences and PTSD, whilst child soldier status did not moderate the mediated effects. These findings support existing evidence of a 'threshold effect,' which means higher exposure to traumatic stressors augments PTSD risk and symptom severity in a dose-response fashion. The current study also highlights the role of both anger and guilt following war experiences and the association with PTSD for both civilians and former child soldiers. Therefore, interventions targeting reducing anger and guilt in war exposed populations are likely to be more effective in treating PTSD. 


\section{Compliance with Ethical Standards}

\section{Funding/Disclosure of Interest:}

Ethical approval: All procedures performed in studies involving human participants were in accordance with the ethical standards of the institutional and/or national research committee and with the 1964 Helsinki declaration and its later amendments or comparable ethical standards.

Informed consent: Informed consent was obtained from all individual participants included in the study. 


\section{References}

Ai, A. L., Peterson, C., \& Ubelhor, D. (2002). War- related trauma and symptoms of posttraumatic stress disorder among adult Kosovar refugees. Journal of Traumatic Stress, 15(2), 157-160.

American Psychiatric Association. (2013). Diagnostic and Statistical Manual of Mental Disorders $\left(5^{\text {th }}\right.$ ed.). Washington, DC: American Psychiatric Association.

Amone-P’Olak, K., Jones, P. B., Abbott, R., Meiser-Stedman, R., Ovuga, E., \& Croudace, T. J. (2013). Cohort profile: Mental health following extreme trauma in a northern Ugandan cohort of War-Affected Youth Study (The WAYS Study). SpringerPlus, 2(1), 1-11.

Amone-P'Olak, K., Jones, P., Meiser-Stedman, R., Abbott, R., Ayella-Ataro, P. S., Amone, J., \& Ovuga, E. (2014). War experiences, general functioning and barriers to care among former child soldiers in Northern Uganda: The WAYS study. Journal of Public Health, 36(4), 568-576.

Andrews, B., Brewin, C. R., Rose, S., \& Kirk, M. (2000). Predicting PTSD symptoms in victims of violent crime: The role of shame, anger, and childhood abuse. Journal of Abnormal Psychology, 109(1), 69-73.

Bayer, C. P., Klasen, F., \& Adam, H. (2007). Association of trauma and PTSD symptoms with openness to reconciliation and feelings of revenge among former Ugandan and Congolese child soldiers. JAMA, 298, 555-559.

Beck, J. G., McNiff, J., Clapp, J. D., Olsen, S. A., Avery, M. L., \& Hagewood, J. H. (2011). Exploring negative emotion in women experiencing intimate partner violence: Shame, guilt, and PTSD. Behaviour Therapy, 42(4), 740-750.

Betancourt, T. S., Borisova, I., Williams, T. P., Meyers- Ohki, S. E., Rubin- Smith, J. E., 
Annan, J., \& Kohrt, B. A. (2013). Research review: Psychosocial adjustment and mental health in former child soldiers - A systematic review of the literature and recommendations for future research. Journal of Child Psychology and Psychiatry, 54(1), 17-36.

Browne, T., Evangeli, M., \& Greenberg, N. (2012). Trauma-related guilt and posttraumatic stress among journalists. Journal of Traumatic Stress, 25, 207-210.

Castillo, D. T., Baca, J. C. D., Conforti, K., Qualls, C., \& Fallon, S. K. (2002). Anger in PTSD: General psychiatric and gender differences on the BDHI. Journal of Loss \&Trauma, 7(2), 119-128.

Catani, C., Jacob, N., Schauer, E., Kohila, M., \& Neuner, F. (2008). Family violence, war, and natural disasters: A study of the effect of extreme stress on children's mental health in Sri Lanka. BMC Psychiatry, 8(1), 33. doi:10.1186/1471-244X-8-33

Chemtob, C. M., Novaco, R. W., Hamada, R. S., Gross, D. M., \& Smith, G. (1997). Anger regulation deficits in combat- related posttraumatic stress disorder. Journal of Traumatic Stress, 10(1), 17-36.

Clark, D. A., \& Beck, A. T. (2010). Cognitive therapy of anxiety disorders. London: The Guilford Press.

Cloitre, M., Roberts, N., Bisson, J., \& Brewin, C. R. The ICD-11 Trauma Questionnaire. Self- Report Community Version 1.4. Unpublished manuscript, XXXXX.

Currier, J. M., Holland, J. M., \& Malott, J. (2015). Moral injury, meaning making, and mental health in returning veterans. Journal of Clinical Psychology, 71(3), 229-240.

Ehlers, A., \& Clark, D. M. (2000). A cognitive model of persistent posttraumatic stress disorder. Behaviour Research and Therapy, 38, 319-345.

Elbert, T., Weierstall, R., \& Schauer, M. (2010). Fascination violence: On mind and brain of 
man hunters. European Archives of Psychiatry and Clinical Neuroscience, 260(2), 100-105.

Ertl, V., Pfeiffer, A., Schauer, E., Elbert, T., \& Neuner, F. (2011). Community-implemented trauma therapy for former child soldiers in Northern Uganda: A randomized controlled trial. JAMA, 306(5), 503-512.

Foa, E. B., Riggs, D. S., Massie, E. D., \& Yarczower, M. (1995). The impact of fear activation and anger on the efficacy of exposure treatment for posttraumatic stress disorder. Behaviour Therapy, 26(3), 487-499.

Ginzburg, K., Butler, L. D., Giese-Davis, J., Cavanaugh, C. E., Neri, E., Koopman, C., ... \& Spiegel, D. (2009). Shame, guilt, and posttraumatic stress disorder in adult survivors of childhood sexual abuse at risk for human immunodeficiency virus: Outcomes of a randomized clinical trial of group psychotherapy treatment. The Journal of Nervous and Mental Disease, 197(7), 536-542.

Hansen, M., Hyland, P., Armour, C., Shevlin, M., \& Elklit, A. (2015). Less is more? Assessing the validity of the ICD-11 model of PTSD across multiple trauma samples. European Journal of Psychotraumatology, 6 doi:http://dx.doi.org/10.3402/ejpt.v6.28766

Hayes, A. F. (2012). PROCESS: A versatile computational tool for observed variable mediation, moderation, and conditional process modeling. [White Paper]. Retrieved from http://

www.afhayes.com/public/process2012.pdf

Hermenau, K., Hecker, T., Maedl, A., Schauer, M., \& Elbert, T. (2013). Growing up in armed groups: Trauma and aggression among child soldiers in DR Congo. European Journal of Psychotraumatology, 4. doi.org/10.3402/ejpt.v4i0.21408

Jakupcak, M., Conybeare, D., Phelps, L., Hunt, S., Holmes, H. A., Felker, B., ... \& McFall, 
M. E. (2007). Anger, hostility, and aggression among Iraq and Afghanistan war veterans reporting PTSD and subthreshold PTSD. Journal of Traumatic Stress, 20(6), 945-954.

Johnson, H., \& Thompson, A. (2008). The development and maintenance of post-traumatic stress disorder (PTSD) in civilian adult survivors of war trauma and torture: A review. Clinical Psychology Review, 28(1), 36-47.

Klasen, F., Oettingen, G., Daniels, J., Post, M., Hoyer, C., \& Adam, H. (2010). Posttraumatic resilience in former Ugandan child soldiers. Child Development, 81(4), 1096-1113.

Klasen, F., Reissmann, S., Voss, C., \& Okello, J. (2015). The guiltless guilty: Trauma-related guilt and psychopathology in former Ugandan child soldiers. Child Psychiatry \& Human Development, 46(2), 180-193.

Kolassa, I. T., Ertl, V., Eckart, C., Kolassa, S., Onyut, L. P., \& Elbert, T. (2010). Spontaneous remission from PTSD depends on the number of traumatic event types experienced. Psychological Trauma: Theory, Research, Practice, and Policy, 2(3), 169-174.

Kubany, E. S., Abueg, F. R., Brennan, J. M., Haynes, S. N., Manke, F. P., \& Stahura, C. (1996). Development and validation of the trauma-related guilt inventory. Psychological Assessment, 8(4), 428-444.

Kubany, E. S., \& Watson, S. B. (2003). Guilt: Elaboration of a multidimensional model. The Psychological Record, 53, 51-90.

Leskela, J., Dieperink, M., \& Thuras, P. (2002). Shame and posttraumatic stress disorder. Journal of Traumatic Stress, 15(3), 223-226.

Litz, B. T., Stein, N., Delaney, E., Lebowitz, L., Nash, W. P., Silva, C., \& Maguen, S. (2009). Moral injury and moral repair in war veterans: A preliminary model and intervention strategy. Clinical Psychology Review, 29(8), 695-706.

Maercker, A., Brewin, C. R., Bryant, R. A., Cloitre, M., Reed, G. M., van Ommeren, M., ...\& 
Saxena, S. (2013). Proposals for mental disorders specifically associated with stress in the International Classification of Diseases-11. The Lancet, 381(9878), 1683-1685.

Marx, B. P., Foley, K. M., Feinstein, B. A., Wolf, E. J., Kaloupek, D. G., \& Keane, T. M. (2010). Combat- related guilt mediates the relations between exposure to combatrelated abusive violence and psychiatric diagnoses. Depression and Anxiety, 27(3), 287-293.

Miller, K. E., \& Rasmussen, A. (2010). War exposure, daily stressors, and mental health in conflict and post-conflict settings: Bridging the divide between trauma-focused and psychosocial frameworks. Social Science \& Medicine, 70(1), 7-16.

Mugisha, J., Muyinda, H., Wandiembe, P., \& Kinyanda, E. (2015). Prevalence and factors associated with Posttraumatic Stress Disorder seven years after the conflict in three districts in northern Uganda (The Wayo-Nero Study). BMC Psychiatry, 15(1), 170. doi:10.1186/s12888-015-0551-5.

Murphy, S., Murphy, J., \& Shevlin, M. (2015). Negative evaluations of self and others, and peer victimization as mediators of the relationship between childhood adversity and psychotic experiences in adolescence: The moderating role of loneliness. British Journal of Clinical Psychology, 54(3), 326-344.

Nazarov, A., Jetly, R., McNeely, H., Kiang, M., Lanius, R., \& McKinnon, M. C. (2015). Role of morality in the experience of guilt and shame within the armed forces. Acta Psychiatrica Scandinavica, 132(1), 4-19.

Neuner, F., Schauer, M., Karunakara, U., Klaschik, C., Robert, C., ... et al. (2004). Psychological trauma and evidence for enhanced vulnerability for posttraumatic stress disorder through previous trauma among West Nile refugees. BMC Psychiatry, 4(34). doi:10.1186/1471-244X-4-34 
Novaco, R. W., \& Chemtob, C. M. (2002). Anger and combat-related posttraumatic stress disorder. Journal of Traumatic Stress, 15(2), 123-132.

O’Donnell, M. L., Alkemade, N., Nickerson, A., Creamer, M., McFarlane, A. C., Silove, D., ... Forbes, D. (2014). Impact of the diagnostic changes to post-traumatic stress disorder for DSM-5 and the proposed changes to ICD-11. The British Journal of Psychiatry, 205(3), 230-235.

Orth, U., \& Wieland, E. (2006). Anger, hostility, and posttraumatic stress disorder in traumaexposed adults: A meta-analysis. Journal of Consulting and Clinical Psychology, 74(4), 698-706.

Owens, G. P., Chard, K. M., \& Cox, TA. (2008). The relationship between maladaptive cognitions, anger expression, and posttraumatic stress disorder among veterans in residential treatment. Journal of Aggression, Maltreatment \& Trauma, 17(4), 439452.

Pham, P., Vinck, P., \& Stover, E. (2009). Returning home: Forced conscription, reintegration, and mental health status of former abductees of the Lord's Resistance Army in northern Uganda. BMC Psychiatry 9:23. doi 10.1186/1471-244X-9-23

Pugh, L. R., Taylor, P. J., \& Berry, K. (2015). The role of guilt in the development of posttraumatic stress disorder: A systematic review. Journal of Affective Disorders, 182, 138-150.

Roberts, B., Ocaka, K. F., Browne, J., Oyok, T., \& Sondorp, E. (2008). Factors associated with post-traumatic stress disorder and depression amongst internally displaced persons in Northern Uganda. BMC Psychiatry, 8(1), 38. doi:10.1186/1471-244X-8-38

Schaal, S., \& Elbert, T. (2006). Ten years after the genocide: Trauma confrontation and posttraumatic stress in Rwanda adolescents. Journal of Traumatic Stress, 19, 95-105.

Silove, D. (1999). The psychosocial effects of torture, mass human rights violations, and 
refugee trauma: Toward an integrated conceptual framework. The Journal of Nervous and Mental Disease, 187(4), 200-207.

Stotz, S. J., Elbert, T., Müller, V., \& Schauer, M. (2015). The relationship between trauma, shame, and guilt: Findings from a community-based study of refugee minors in Germany. European Journal of Psychotraumatology, 6. doi:10.3402/ejpt.v6.25863

UNICEF. (2010). B\&H post-war screening survey. UNICEF: New York.

Vinck, P., Pham, P. N., Stover, E., \& Weinstein, H. M. (2007). Exposure to war crimes and implications for peace building in northern Uganda. JAMA, 298(5), 543-554.

Weierstall, R., Bueno Castellanos, C. P., Neuner, F., \& Elbert, T. (2013). Relations among appetitive aggression, post-traumatic stress and motives for demobilization: A study in former Colombian combatants. Conflict and Health, 7(9) doi: 10.1186/1752-15057-9

Weierstall, R., Schaal, S., Schalinski, I., Dusingizemungu, J. P., \& Elbert, T. (2011). The thrill of being violent as an antidote to posttraumatic stress disorder in Rwandese genocide perpetrators. European Journal of Psychotraumatology, 2. doi.org/10.3402/ejpt.v3i0.63 